Revista Destaques Acadêmicos, Lajeado, v. 9, n. 4, 2017. ISSN 2176-3070 DOI: http://dx.doi.org/10.22410/issn.2176-3070.v9i4a2017.1651 www.univates.br/revistas

\title{
ENSINAR QUÍMICA NA EDUCAÇÃO PROFISSIONAL E TECNOLÓGICA: EXPERIÊNCIA PROPORCIONADA PELO ESTÁGIO SUPERVISIONADO
}

\author{
Vanessa Sales da Silva Coelho ${ }^{1}$, Marcelo Franco Leão ${ }^{2}$
}

Resumo: O presente estudo tem como objetivo relatar as experiências vivenciadas durante a realização do estágio supervisionado requerido pelo Curso do Ciências da Natureza com Habilitação em Química, do Instituto Federal de Educação, Ciência e Tecnologia de Mato Grosso (IFMT) Campus Confresa, em Mato Grosso. Trata-se de um relato de experiência cuja abordagem é qualitativa. Sua realização ocorreu durante os meses de junho, julho e agosto de 2016 em turmas do $1^{\circ}$ e $2^{\circ}$ anos do Ensino Médio Técnico dos cursos de Agroindústria e Agropecuária do IFMT Campus Confresa. $\mathrm{O}$ estudo permitiu realizar reflexões sobre as estratégias de ensino que favorecem a construção de aprendizagem significativa, sobre a educação profissional no Brasil. Além da descrição da instituição de ensino e das atividades docentes realizadas, o estudo possibilitou compreender as contribuições que o estágio supervisionado proporcionam para a construção da identidade profissional.

Palavras-chave: Estágio supervisionado. Identidade profissional. Ensino de química.

\section{INTRODUÇÃO}

Falar da importância do estágio para formação docente não é tarefa difícil. Difícil, é imaginar o ser professor sem antes passar por essa experiência. O estágio supervisionado é uma etapa decisiva e fundamental na formação de um professor. É nessa fase da formação de um estudante de licenciatura que o "ser professor" se revela mais evidentemente. Sua importância é entendida nas palavras de Pimenta e Lima (2010), quando se referem ao estágio

1 Graduada em Licenciatura em Ciências da Natureza - Habilitação em Química pelo Instituto Federal de Mato Grosso (IFMT) Campus Confresa.

2 Graduado em Química pela UNISC e em Licenciatura em Física pela UNEMAT. Pós-graduado em Orientação Educacional (Dom Alberto) e em Relações Raciais na Educação e na sociedade Brasileira (UFMT). Mestre em Ensino pela UNIVATES. Doutorando em Educação em Ciências pela UFRGS. Professor do Departamento de Ensino do IFMT Campus Confresa. 
supervisionado não apenas como a parte prática do curso, mas como um campo de conhecimento.

O estágio é de fato indispensável à formação docente, pois se trata da materialização da profissão escolhida, da construção da identidade profissional. Segundo Pimenta e Lima (2004, p. 02), o estágio supervisionado permite refletir "questões básicas [...]: o sentido da profissão, o que é ser professor na sociedade em que vivemos, como ser professor, a escola concreta, a realidade dos alunos nas escolas de ensino fundamental e médio, a realidade dos professores nessas escolas, entre outras".

Em outras palavras, passar pelo estágio supervisionado permite ao acadêmico em formação praticar todo o aprendizado construído dentro de sala. Trata-se de um momento de unificação entre teoria e prática, numa relação importantíssima na formação do professor (PICONEZ, 2012).

Importante dizer que, o estágio supervisionado é apenas o início do processo de construção da identidade profissional. Assim, há um aspecto a ser considerado nessa fase de construção da identidade do professor: ter conhecimentos da área de referência não é sinônimo de saber ensinar. Com relação a atuação do professor, Masetto (2003) diz que não é suficiente o domínio de um conteúdo para entrar em sala e conseguir que os estudantes aprendam, é preciso ter estratégias, sim no plural, pois segundo ele, o processo de aprendizagem exige muito dos estudantes, então é preciso muita estratégia para que todos os objetivos propostos sejam alcançados.

A realização do estágio docente está prevista na Lei de Diretrizes e Bases da Educação Nacional (LDB 9394/96) como parte obrigatória dos cursos de Licenciatura. Assim, é componente curricular do Curso do Ciências da Natureza com Habilitação em Química, do Instituto Federal de Educação, Ciência e Tecnologia de Mato Grosso (IFMT) Campus Confresa. Além da obrigatoriedade preconizada em lei, o curso se preocupa em garantir que esse momento formativo seja realizado da melhor maneira possível. O estágio supervisionado contribui na construção da identidade dos futuros profissionais da educação, ou seja, esse é um momento que promove aprendizagens significativas ao licenciando.

De acordo com a LDB, o estágio supervisionado compreende uma carga horária mínima de 400 horas. Segundo o Projeto Pedagógico do Curso, essa carga horária é dividida em dois momentos: o primeiro consiste na observação da prática docente em sala de aula (120 horas), e o segundo de regência de aula acompanhado de um professor supervisor (280 horas). Esses dois momentos proporcionam experiências e aprendizados adquiridos enquanto no exercício da docência.

Esse estágio supervisionado relatado foi desenvolvido na própria instituição formadora. O IFMT Campus Confresa faz parte da Rede Federal de Educação Profissional, Científica e Tecnológica instituída pela lei 11.892 de 29 
de dezembro de 2008, Lei de criação do Institutos Federais e estabelecida pela Portaria n 04 de 06 de janeiro de 2009, do Ministério da Educação.

A primeira experiência com o local de atuação profissional (observação), ocorreu no período de 25 de abril a 18 de maio de 2016 e totalizou 120 horas, dividido em duas partes, sendo 60 horas atribuídas à observação em sala, em turmas do $1^{\circ}$ e $2^{\circ}$ anos do Ensino Médio Técnico nos cursos de Agroindústria e Agropecuária, nos períodos matutino e vespertino, e as outras 60 horas foram destinadas a leitura dos Projetos Pedagógicos dos Cursos e de bibliografias, além do levantamento de informações inerentes à Instituição de ensino, tais como espaço físico e pessoal e à confecção de relatório já devidamente concluído.

Ainda no período de observação das aulas, pude perceber a dificuldade dos estudantes em relação à disciplina de química, como se esta fosse algo muito distante de suas realidades. Mas pude perceber também os olhares curiosos e a atenção voltada às aulas expositivas da professora quando ela com sucesso os aproximava do conteúdo através de exemplos simples do cotidiano, de forma que a dificuldade deles aos poucos ia se desfazendo. Isso foi o que procurei fazer quando estava lá: deixar a química o mais próximo possível do dia a dia dos estudantes, tanto nas aulas expositivas quanto em aulas práticas e demonstrações simples.

Todas as informações e conhecimentos adquiridos na observação, serviram de base para um segundo momento de 280 horas de regência. Nessa outra etapa, 72 horas foram destinadas a regência em sala de aula, 72 horas usadas para preparação das aulas, 20 horas destinadas a atividades de redação do relatório de regência, leitura dos documentos da instituição e demais leituras necessárias a confecção do presente relatório, sendo que as demais 140 horas foram ocupadas com o projeto de iniciação científica, conforme permite o PPC do curso.

Este estudo é parte do Trabalho de Conclusão de Curso, o qual foi defendido em maio de 2017. Trata-se de um relato de todo esse universo de experiências que pude vivenciar nesse período de estágio supervisionado de regência.

Para melhor organizar este texto, em seguida é apresentada uma breve reflexão sobre as estratégias de ensino como fator decisivo para construção de aprendizagem significativa com uma breve comparação com a experiência vivida. Na sequência, é feita uma abordagem da educação profissional no Brasil. Em outro momento é realizada a descrição do local em que foi realizado o estágio supervisionado e das atividades desenvolvidas. Por fim, é realizada uma reflexão sobre os maiores aprendizados proporcionados pelo estágio supervisionado na construção da identidade profissional. 


\section{ESTRATÉGIAS DE ENSINO E A APRENDIZAGEM SIGNIFICATIVA}

Ao optar por ser professor, é estar ciente dos desafios inerentes a profissão. Aqui, essa afirmação não está baseada em salários, desvalorização dos profissionais, condições de trabalho, entre outros tantos desafios, mas no simples fato de estar em uma sala de aula: quarenta estudantes diferentes entre si, porém parte de um todo e um professor para quarenta individualidades que precisam funcionar em conjunto.

Campos (2009) traz uma reflexão interessante quando diz que quem já foi estudante certamente já tem um prévio conhecimento do que é ser professor:

Os saberes de sua experiência de aluno que foram de diferentes professores em toda sua vida escolar. Experiência que lhe possibilita dizer quais foram os bons professores, quais eram bons em conteúdo, mas não em didática, isto é, não sabiam ensinar. Quais professores foram significativos em suas vidas, isto é, contribuíram para sua formação humana (CAMPOS, 2009, p. 20).

Essa visão de que o estudante constrói de seus professores ao longo de sua vida escolar revela a importância das estratégias de ensino adotadas por estes, uma vez que as estratégias são como a identidade do professor, através das quais serão lembrados. Nesse sentido, é preciso que o aspirante a docente tenha em mente a preocupação em trabalhar as propostas do currículo escolar, inovando a relação professor-estudante-conhecimento (ANASTASIOU; ALVES, 2003).

Segundo Moreira (2010), a melhor das estratégias a ser usada em sala é a da aprendizagem significativa, ou seja, todo e qualquer esforço deve estar concentrado na verdadeira aprendizagem, aquela que o estudante leva para a vida. Essa preocupação esteve bem presente em meu período de estágio. A todo momento procurava me certificar de que a turma estava realmente aprendendo, e essa certeza vinha quando os próprios estudantes conseguiam se manifestar sobre o assunto discutido e principalmente quando associavam aquele conhecimento às suas próprias experiências.

Os termos estratégias de ensino e aprendizagem significativa estão profundamente ligados, afinal, o objetivo de um é alcançar o outro. "Assim o professor deve ser um verdadeiro estrategista, no sentido de estudar, selecionar, organizar e propor as melhores ferramentas facilitadoras para que os estudantes se apropriem do conhecimento" (ANASTASIOU; ALVES, 2003, p.02).

Mas o que seriam essas estratégias? Para Masetto (2003) são os meios que o professor utiliza em aula para facilitar a aprendizagem dos estudantes, para tanto, lançando mão de técnicas como aulas expositivas e práticas, recursos tecnológicos, visitas técnicas, dinâmicas, leituras, entre outros. 
Segundo Alves e Anastasiou (2003), as estratégias de ensino também envolvem relações e postura do professor, afinal, se o professor adota uma postura tradicional cujo a memorização é a principal operação, usar recursos como os acima citados, podem não surtir o efeito desejado, porque a metodologia vai continuar sendo a mesma.

Ainda no período de observação das aulas, pude perceber que, mesmo com a dificuldade dos estudantes em relação à disciplina de química, as suas atenções eram voltadas à professora. Ela com sucesso os aproximava do conteúdo, independentemente de como a aula era ministrada, de forma que o preconceito deles aos poucos ia se desfazendo à medida que a curiosidade ia sendo aguçada.

Como já dito anteriormente, uma sala de aula tem um professor e umas quarenta individualidades a serem consideradas. Nesse sentido, o conhecimento do estudante é essencial para a escolha da estratégia, com seu modo de ser, agir, estar e sua dinâmica pessoal (ANASTASIOU; ALVES, 2003).

Nessa mesma linha de pensamento, Mazzioni descreve essa interação a ser considerada pelo professor da seguinte maneira:

A atividade docente é caracterizada pelo desafio permanente dos profissionais da educação em estabelecer relações interpessoais com os educandos, de modo que o processo de ensino-aprendizagem seja articulado e que os métodos utilizados cumpram os objetivos a que se propõem (MAZZIONI, 2013 p.01).

Nesse contexto, observa-se o método tradicional não atende as expectativas atuais de ensino. A necessidade de formar pensadores exige estratégia por parte dos professores. Anastasiou e Alves (2003) fala sobre uma das opções disponíveis ao professor, a metodologia dialética:

$\mathrm{Na}$ metodologia dialética como já discutido o docente deve propor ações que desafiem ou possibilitem o desenvolvimento das operações mentais; para isso organiza os processos de apreensão de tal maneira que as operações de pensamento sejam despertadas, exercitadas, construídas, flexibilizadas pelas necessárias rupturas, através da mobilização, da construção e das sínteses, a serem vistas e revistas, possibilitando ao estudante sensações ou estados de espírito carregados de vivência pessoal e de renovação (ANASTASIOU; ALVES, 2003 p.02).

Em outras palavras, o estudante precisa participar da construção do saber, de forma que o conhecimento fique mais próximo de suas experiências, para que ele possa questioná-las e observá-las com novo olhar, tornar-se crítico. 


\section{A EDUCAÇÃO TÉCNICA PROFISSIONAL NO BRASIL}

A educação técnica profissionalizante não é uma novidade dos dias atuais. A ideia surge no país em meados do século XIX, com o Colégio das fábricas criado por D. João VI, quando ainda era príncipe regente. "Portanto, a Educação Profissional origina-se predominantemente na sociedade civil e com objetivos assistencialistas, para que seus destinatários se afastassem de ações na contraordem dos bons costumes" (MOURA, 2008 p. 02). Surge então o conceito teórico-prática que se sustenta até hoje, porém com finalidades diferentes, acrescido de estudos e pesquisas desenvolvidas ao longo dos anos para seu aperfeiçoamento.

Atualmente, a Educação profissional tem muitas diretrizes, dentre elas, destaca-se a Lei 9.394 de 20 de dezembro de 1996 (LDB), que trata das diretrizes Curriculares Nacionais para a educação Profissional de nível técnico. Logo de início, no Art. $1^{\circ}, 2^{\circ}$ parágrafo, já diz que "A educação escolar deverá vincularse ao mundo do trabalho e à prática social". Em seguida, no seu artigo $2^{\circ}$, encontramos mais um momento de relação teórico prática:

Art. $2^{\circ}$ - A Educação, dever da família e do Estado, inspirada nos princípios de liberdade e nos ideais da solidariedade humana, tem por finalidade o pleno desenvolvimento do educando, seu preparo para o exercício da cidadania e sua qualificação para o trabalho.

Dessa forma, torna-se bem explícito a forma com a qual a educação profissionalizante é ponto importante nesta lei, que trata da educação brasileira.

Essa modalidade de educação profissionalizante tem sido muito empregada de forma integrada ao ensino médio no seguimento científico e tecnológico, onde, segundo Berger Filho (1999, p. 06):

(...) a educação geral seja concebida como educação de base científica e tecnológica, onde conceito, aplicação e solução de problemas concretos sejam combinados a uma revisão do papel dos componentes socioculturais, que por sua vez devem ter uma visão epistemológica que concilie humanismo e tecnologia ou humanismo numa sociedade tecnológica.

Esse é o modelo de ensino profissionalizante usado na Rede Federal de Educação Profissional, Científica e Tecnológica instituída pela lei 11.892 de 29 de dezembro de 2008, Lei de criação dos Institutos Federais. O Projeto Pedagógico do Curso Técnico em Agroindústria ofertado pelo Instituo Federal de Mato Grosso Campus Confresa, o qual faz parte dessa Rede, fala das finalidades dos Institutos Federais:

Estes, ao atuarem em todos os níveis e modalidades da Educação Profissional, poderão contribuir para o desenvolvimento local e 
regional, bem como garantir a difusão dos conhecimentos científicos, a ligação com os arranjos produtivos locais e a formação do cidadão trabalhador (IFMT, 2014).

Aqui, o destaque para os Institutos Federais se dá pelo fato de que os mesmos tornam a ideia de teórico-prática ainda mais interessante, pois, a oferta da educação profissional tecnológica com a finalidade de contribuir para que estudantes sejam os agentes de mudança da própria realidade, traduz o sentido de Educação Técnica Profissional.

\section{DESENVOLVIMENTO DAS ATIVIDADES DOCENTES}

O Estágio de Regência foi realizado no Instituto Federal de Mato Grosso Campus Confresa durante o primeiro semestre do ano letivo de 2016. Seu início se deu em nove de junho sendo concluído em dez de agosto, totalizando uma carga horária de 280 horas. Desse total, 72 horas foram de aulas ministradas, 72 horas de preparação dessas aulas, 20 horas destinadas a leituras e confecção do presente relatório, e 140 horas dedicadas ao projeto de iniciação científica "Avaliação da atividade biológica do óleo essencial de plantas medicinais aromáticas da região Araguaia - Xingu" - Edital IFMT n 006/2015, bem como no projeto "Capacitação em Boas Práticas Laboratoriais", ambos com participação voluntária.

\subsection{Caracterização da Instituição de Ensino}

Os cursos ofertados pelo IFMT Campus Confresa são: Ensino Médio Integrado Presencial nas áreas Técnico em Agropecuária, Técnico em Agroindústria e Técnico em Alimentos (em processo de extinção), todos em período integral diurno, e Cursos Técnicos noturnos, em Comércio na modalidade PROEJA e em Controle Ambiental na modalidade Subsequente. Em nível de graduações, a instituição oferece os cursos de Bacharelado em Agronomia em período integral diurno e Licenciatura em ciências da natureza nas áreas de Química, Física e Biologia, todas no período noturno. Além disso, também são ofertadas duas Pós-graduações Lato Sensu, uma em Educação do Campo e a outra em Ensino de Ciências. Atualmente a escola possui em torno de 120 profissionais e atende anualmente cerca de 1.000 estudantes, sendo a única escola Federal na região do Baixo Araguaia.

Importante dizer que a Instituição recebe estudantes das zonas urbana e rural do município de Confresa e de municípios vizinhos. Alguns desses estudantes vêm de ônibus, e outros são contemplados com alojamento, auxílio moradia e/ou bolsas ofertadas pelo campus. 


\subsection{Espaço físico}

Em relação ao espaço físico, o ambiente é dividido em Administrativo, que compreende os setores de Direção Geral, Administrativo, Recursos Humanos, Contratos e Convênios, Tecnologia da Informação, Patrimônio e Almoxarifado, Contabilidade, Compras e Licitações, Jornalismo, Pesquisa e Pós Graduação, Extensão e Prefeitura, e em Departamento de Ensino, composto por Registro Escolar, Direção de Ensino, Reprografia, Centro de Assistência ao Educando (CAE), Núcleo de Atendimento a Pessoa com Necessidade Específica (NAPNE), laboratórios de Química, Bromatologia, Entomologia, Analise Sensorial, Alimentos, Física e Matemática, Solos e Informática, 03 sala de professores e 16 salas de aulas, Biblioteca equipada com Sala de Vídeo, Centro de Convivência, Restaurante, 02 alojamentos sendo 01 feminino e 01 masculino, 03 Unidades de Estudo Pratico (UEP) e Guarita, além de uma área de lazer gramada e arborizada. A área total construída é de aproximadamente $8.236,64 \mathrm{~m}^{2}$ num terreno que se aproxima dos 50.072 hectares, conforme dados fornecidos pelo setor de Serviços Auxiliares do próprio campus.

Em sua estrutura, o prédio possui alguns lugares com acessibilidade na forma de rampas, banheiros para pessoas com necessidades especiais, portas largas que possibilitam a passagem de cadeirantes e corrimão em pontos estratégicos do prédio, além da equipe de apoio, como psicóloga, assistente social, enfermeira e servidores da Coordenação de Assistência ao Educando.

Com exceção de uma ou outra sala, quase todos os espaços possuem ar condicionado. As salas de aula possuem quadro branco de vidro, cortinas nas janelas, mesa e cadeira de professores e assentos suficientes para estudantes, sendo que em algumas salas cadeiras de polipropileno com braço e em outras são conjuntos de mesa e cadeira de madeira. Algumas salas possuem também guarda volumes para auxilio dos estudantes.

\subsection{Recursos didáticos e Outros}

Após levantamento material, constatou-se que a instituição é bem equipada em relação a móveis e eletrônicos como computadores, telefones, retroprojetores multimídia, computadores interativos, caixa de som e impressoras, além de contar com internet tanto para servidores quanto para estudantes e com um rico e diversificado acervo bibliográfico. A escola possui veículos de passeio a serviço da instituição e ônibus para viagens técnicas, tratores agrícolas munidos de acessórios, além disso conta com materiais esportivos como bolas, redes, aparelhos de academia, e materiais de lazer como jogos de xadrez, instrumentos musicais, mesa e acessórios de pingue-pongue.

Quanto ao quadro de pessoal, até a data de confecção do presente relatório, o IFMT Campus Confresa conta com 53 docentes, 41 técnicos administrativos, 08 estagiários e 21 terceirizados. 


\subsection{O Estágio de Regência}

O estágio supervisionado de regência é o momento no qual o estudante estagiário, acompanhado por um professor regente, realiza atividades de docência, ou seja, exerce as funções de um professor em sala de aula. As minhas atividades foram desenvolvidas em três turmas do $1^{\circ}$ Ano, e uma turma do $2^{\circ}$ Ano, todas no Ensino Médio Integrado Presencial, nos cursos Técnicos em Agropecuária e Agroindústria, no IFMT Campus Confresa. As aulas ministradas foram na disciplina de Química, nos períodos matutino e vespertino.

Importante dizer que, nesse meio tempo de ocorrência do estágio, houve o período de férias dos estudantes e que as tardes de quarta-feira eram destinadas à reposição de aulas para devido cumprimento do calendário escolar. Assim, a quantidade total de aulas ministrada por semana era de 09 aulas, sendo duas aulas nos $1^{\circ}$ Ano e $2^{\circ}$ Ano do Curso de Agropecuária, três aulas no $1^{\circ}$ ano do Curso de Agroindústria, semanalmente.

Em nossos encontros nos dias de aula, eu a minha supervisora quase sempre tirávamos um momento na sala de professores para falar sobre as turmas, sobre como tentar amenizar a diferença de rendimento entre elas, sobre o comportamento de alguns estudantes e as causas da indisciplina, e se as aulas estavam sendo produtivas. O planejamento das aulas também ocorria nesses momentos, quando juntas analisávamos a ementa e o material didático que tínhamos disponível.

A preparação das aulas em si era de minha autoria: Primeiro víamos qual o conteúdo a ser trabalhado e, em seguida, eram passadas as orientações necessárias, como os principais pontos a serem trabalhados, se era preciso ou não revisar um ou outro conceito, quais atividades eram interessantes para o contexto trabalhado, em quais momentos trabalhar com práticas.

De posse dessas informações, eu tinha total liberdade para preparar as aulas. Essa autonomia me proporcionou mais confiança nos momentos de explicação do conteúdo. Já com relação as atividades, tive dificuldades quanto as correções - em sua maioria a supervisora o fazia e eu só acompanhava - e demorei bastante para entender como avaliar os estudantes.

Sobre o andamento do estágio propriamente dito, não conversávamos muito, mas percebia a atenção da supervisora nos momentos em que me observava. Os comentários avaliativos aconteciam quando era preciso melhorar em algum ponto.

\subsection{Aulas Ministradas e Caracterização das Turmas}

Durante o período em sala, foram 72 horas/aula ministradas no decorrer de 16 dias. $\mathrm{O}$ começo do estágio regência coincidiu com o final do $2^{\circ}$ bimestre. Assim, em todas as turmas, o meu começo foi com revisão dos conteúdos e aplicação de provas, o que me ajudou bastante na interação inicial com os 
estudantes. Para melhor compreensão das minhas experiências em cada turma, a partir daqui falaremos de cada uma delas separadamente.

As aulas com a turma do $1^{\circ}$ ano de agropecuária se iniciaram no dia 09 de junho e encerraram no dia 10 de agosto de 2016. Em 16 aulas (8 dias), além de revisão e prova, trabalhamos com os temas: Estados Físicos da Matéria; Substâncias puras e misturas; Densidade; Separação de misturas e Segurança no laboratório. De início, percebi uma turma agitada e ainda eufórica pelo ingresso, afinal ainda estavam nos primeiros seis meses de IFMT. Trabalhamos com atividades em sala, dinâmicas, atividades para casa e aulas práticas em sala.

Nessa turma, pude perceber que as dinâmicas propostas davam certo, porém era bem trabalhoso desenvolvê-las, porque os estudantes conversavam bastante. Nesse sentido, como sugere Anastasiou e Alves (2003) ao dizer que o professor tem que ser um verdadeiro estrategista, procurei colocar essa euforia a nosso favor.

Uma das estratégias usada foi deixá-los participar da explicação, fazendo com que eles ficassem à vontade para tentar relacionar o conteúdo com exemplos do próprio cotidiano, afinal, a conversa quando é produtiva, não atrapalha. A aula prática proposta em sala foi outra estratégia que deu certo, pois percebi que os estudantes conseguiram entender melhor a teoria após o experimento, num momento que proporcionou interação e dinâmica entre mim e os estudantes, e entre eles.

Nessa turma, iniciamos no dia 10 de junho e encerramos em 15 de julho de 2017. Assim como na turma "A", após a revisão e a prova, trabalhamos com os temas: Estados Físicos da Matéria; Densidade; substâncias puras e misturas; Separação de misturas e Segurança no laboratório. Entre as turmas do $1^{\circ}$ ano, essa era a mais tranquila, possibilitando o andamento dos trabalhos, de forma que se adiantava em relação a outra turma de agropecuária.

Nessa turma o fato de conseguir adiantar bem os conteúdos, não me trazia satisfação ao final das aulas. Isso porque a turma não interagia muito, não gostavam de opinar ou questionar. Sendo assim, sentia que não conseguia envolve-los suficientemente para que se sentissem à vontade para se expressarem. Assim como sugere Moreira (2010), a minha preocupação era que a aprendizagem fosse significativa.

Na turma de agroindústria os encontros eram um pouco mais demorados, sendo 03 aulas por dia no período de 10 de junho a 15 de julho de 2017, o que permitia trabalhar o conteúdo com mais calma. Os temas trabalhados foram os mesmos das duas turmas anteriores, porém a dinâmica de sala era maior, devido ao maior envolvimento e participação dos estudantes. A turma também era mais agitada, o que resultava em atraso no andamento do conteúdo, porém possibilitava maior interação entre nós todos e entre os próprios estudantes. 
Aqui também trabalhamos com atividades, dinâmicas e experimentos em sala. As atividades práticas propostas no ambiente da sala de aula, proporcionaram momentos de conhecimento aplicado e ilustração da teoria, resultando em uma melhor aprendizagem do conteúdo pelos estudantes. Foi gratificante perceber como eles gostaram desses momentos, dos quais faziam questão de tecer comentários positivos, relembrando a experiência.

Nessa turma, houve problemas de comportamento com dois estudantes, porém a instituição conta com a Coordenação de Assistência ao Educando (CAE), que oferece esse suporte. Dessa forma, questões dessa natureza eram resolvidos rapidamente. Mesmo assim, procurei não abandonar a metodologia dialética sugerida por Anastasiou e Alves (2003), por entender que a vivência pessoal de cada estudante também faz parte do contexto da aprendizagem. Pode ser que não tenha sido um bom dia para esses estudantes, e não uma característica de comportamento.

Falando das turmas de $1^{\circ}$ ano de forma geral, posso dizer encontrei facilidade em desenvolver o conteúdo programado, sendo que a dificuldade maior encontrada nessas turmas foi à dificuldade na escrita por parte dos estudantes. Também quando havia atividade extraclasse, era possível perceber que a maioria das respostas eram exatamente iguais, ou seja, a maioria não tentava fazer, apenas copiava do colega.

Para esse último caso, procurávamos interagir na hora da correção dessas atividades em sala, envolvendo os estudantes, para melhor compreensão do conteúdo. Com tempo, também percebi que os trabalhos em sala, não era muito viável formar grupos pois resultava em desordem, então trabalhávamos no máximo em duplas, deixando agrupamentos para trabalhos extraclasse.

A única turma de $2^{\circ}$ ano com a qual trabalhei foi a do $2^{\circ}$ ano - Agropecuária "A". Foram oito encontros, no período de 09 de junho a 10 de agosto de 2017. Os conteúdos ministrados foram: Diluição de soluções e titulação de neutralização; Estequiometria; Termoquímica; Entalpia e lei de Hess.

No início, tivemos revisão do conteúdo de Soluções e Solubilidade e, na sequência, fomos ao laboratório para uma aula prática com título "Usando a solubilidade de sais para descobrir o conteúdo de soluções incolores". Essa aula foi preparada pela supervisora, sendo que fiquei somente para auxiliar, mas foi possível perceber o empenho e a satisfação dos estudantes em estarem ali.

Trabalhamos com demonstrações, dinâmicas e atividades em sala. Essas demonstrações foram propostas com o intuito de proporcionar a construção dos aprendizados químicos e vem ao encontro do pensamento de Masetto (2003) que acredita que o professor necessita variar suas estratégias de ensino para facilitar o aprendizado.

Essa turma era bastante calma e tudo que me propus a fazer teve grande aceitabilidade por parte dos estudantes, resultando em objetivos alcançados. 
Percebi ainda, bastante empenho da turma em relação em desenvolver atividades e tirar dúvidas. O problema das atividades extraclasse que havia nas turmas de $1^{\circ}$ ano também ocorria aqui, porém em menor quantidade, encarado por mim como mais um desafio da profissão, como sugere Mazzioni (2003).

\subsection{Avaliação da aprendizagem e do Estágio}

O quesito avaliação foi um dos pontos mais difíceis para mim. Desde o princípio dividi essa preocupação quanto a avaliar o estudante com a minha supervisora, pois, mesmo após observá-la nas avaliações, minha insegurança era muito grande. O período inicial do meu estágio supervisionado de regência coincidiu com o fechamento do primeiro bimestre, ou seja, na semana de provas. Assim, como as avaliações já estavam elaboradas, apenas acompanhei sua aplicação e, posteriormente, a correção pela professora regente.

Durante as aulas ministradas, trabalhei com exercícios em sala e extraclasse também. A correção de tais atividades foi muito trabalhosa, pois muitos questionamentos surgiam, sendo o principal deles a dúvida: será que estou sendo justa? Já nas dinâmicas em sala, achei mais fácil de avaliar, pois o comportamento e atitude do estudante diz muito sobre ele.

Nas minhas últimas aulas em cada turma, pedi que, sem se identificar, cada estudante elaborasse um texto me avaliando como professora. Optei por esse método por entender que a aplicação de um questionário tornaria esse momento muito objetivo, sendo que gostaria que houvesse maior liberdade para expressarem como foi esse nosso momento. Preciso dizer que tive gratas surpresas ao ler os textos, que traziam os seguintes trechos:

"Suas explicações ficaram claras, e é muito enturmada com os alunos. Não irei esquecê-la, pois foi com ela que aprendi regra de três" (A2).

"[...] sou uma aluna que tem muita dificuldade em química, porém é muito fácil entender a sua explicação" (A5).

"[...] a professora consegue manter a calma mesmo com a sala toda fazendo bagunça e isso nos traz muita confiança [...]" (A6).

"As aulas foram muito boas, pois a professora explica muito bem, a última aula foi a melhor aula de química que já tive!" (A12).

"Com a professora estagiária dando aula, eu consegui compreender mais a matéria, procura fazer os alunos compreenderem a matéria e isso foi muito importante" (A19).

"Suas aulas são bem dinâmicas e prazerosas. Instiga a pessoa a buscar o conhecimento" (A23).

"A professora estagiária dá muitos exemplos quando vai explicar um conteúdo, isso é muito bom, assim a gente se interessa mais. As dinâmicas que ela faz são bem divertidas, isso deixa mais fácil o conteúdo" (A25). 
"Primeiramente acho a senhora uma ótima professora que tenta entender os alunos, explica quantas vezes for necessário para entendermos" (A26).

Esses relatos me deixaram bastante emocionada e ao mesmo tempo feliz por saber que houve aprendizagens significativas, que era meu maior objetivo. Não houve pontos negativos sobre meu desempenho no relato dos estudantes, apenas um conselho:

“Eu não achei defeito nenhum nas aulas. O que pode ser mudado é o jeito de chamar a atenção dos alunos, tipo, ao invés de bater na mesa ou alterar a voz, você combina com os alunos que quando você estiver falando não quer ouvir ninguém conversando" (A11).

Gostei bastante de ler esse trecho porque foi construtivo. Com certeza vou me lembrar disso em minha próxima oportunidade em sala de aula.

\subsection{Percepções do estágio}

Entrar em sala de aula pela primeira vez como professora foi uma sensação única. Em meu primeiro dia não fiquei nervosa, porém bastante ansiosa. Lembro-me que cheguei dez minutos mais cedo, peguei o computador interativo e fiquei aguardando o momento de entrar em sala. Os dez minutos pareciam ser uma eternidade e, depois que eu estava lá dentro, o tempo passou que eu nem vi.

Nesse primeiro momento em sala, a importância da observação que antecedeu o estágio regência fica bem evidente, pois, o fato de estar diante de turmas as quais eu já vinha analisando e tentando entender há algum tempo, bem como a familiarização com o conteúdo que vinha sendo ministrado, me proporcionou confiança e me ajudou na interação com os estudantes.

Durante o estágio regência, me deparei com algumas dificuldades enquanto professora, a principal delas foi a dependência do retroprojetor multimídia ou computadores interativos. A maioria das minhas aulas foram preparadas utilizando projeções, de forma que, quando eu utilizava de outros recursos, não conseguia desenvolver muito bem o conteúdo devido à falta de tempo hábil.

O fato das salas serem cheias com uma média de 40 adolescentes por turma era a principal causa, pois eu me sentia arrasada quando não conseguia atingir o objetivo da aula, e sem esse recurso midiático, eu mal conseguia falar em meio a muita conversa. Aos poucos fui me adaptando e, nas últimas aulas consegui trabalhar sem o equipamento com aulas bem produtivas.

Em relação aos estudantes, também tive algumas percepções que descreverei. Primeiro foi a aversão que grande maioria tem em relação à disciplina de química, que acaba por formar uma barreira que impede a aprendizagem. Aos poucos, fui tentando trabalhar essa questão, assim como a minha supervisora fazia, relacionando a química com exemplos práticos do dia 
a dia, o que me levou a obter resultados positivos. Outra questão com a qual me deparei em todas as turmas, foi a dificuldade com a escrita que boa parte dos estudantes apresenta. Essa foi uma barreira para mim, pois não soube o que fazer nessa situação.

Muitos pontos positivos também devem ser registrados aqui. O primeiro deles foi a aceitação que eu tive na instituição quanto estagiária. Recebi apoio e suporte imediato por parte do IFMT Campus Confresa e fiquei bastante feliz com a receptividade dos estudantes que demonstraram respeito e carinho pela minha pessoa, me tratando como se de fato eu fosse uma professora, mesmo sabendo que eu estava ali para aprender a ser uma. Além disso, o espaço físico e a estrutura da escola não deixam a desejar, bem como o interesse da instituição em incentivar a formação de pesquisadores, através de feiras, eventos, workshops, congressos, todos voltados a esse objetivo.

Ao final do processo, me dei conta que não havia registrado, por meio de fotos, os momentos da regência nas salas de aula. Isso foi devido ao tamanho envolvimento que estava, pois minha prioridade era que as aulas realmente fizessem sentido aos estudantes e não apenas cumprimento de currículo. A partir dessa observação, consegui perceber como foi bom estar com aqueles estudantes, tão bom que a hora passava muito rápido, ocasionando tal esquecimento.

\section{CONSIDERAÇÕES FINAIS}

O estágio supervisionado, especialmente durante a regência em sala de aula, enriqueceu de forma considerável a minha definição dos termos "ensinar" e "aprender", de forma que, após essa experiência entendo que ambos são um único processo e que este define o que é ser professor. Apesar de ter sido por pouco tempo, o estágio funcionou como uma prévia daquilo que me espera nessa futura profissão.

Durante esse momento formativo, foi possível sentir desde o peso da responsabilidade em educar até os sentimentos de sucesso ou de frustração após sair de uma sala de aula. Nesse sentido, a necessidade de usar estratégias de ensino fica bastante evidente, pois é capaz de tornar o momento em sala de aula muito mais prazeroso e produtivo. Para mim, olhar para o processo de ensino-aprendizagem do ponto de vista de um professor, sendo ainda aluna, trouxe um sentimento de privilégio, como se eu pudesse visualizar tal processo com um ângulo de $360^{\circ}$, ou seja, como um todo.

Ensinar química em cursos profissionalizantes não foi tão simples como parecia. Logo me dei conta da importância que essa disciplina representa para os cursos técnicos em Agropecuária e em Agroindústria, uma vez que é base para as disciplinas específicas dos cursos. Saber que tive uma parcela de contribuição na formação desses futuros profissionais é gratificante, visto 
que se trata de futuros agentes de mudança da realidade de nosso município e região.

A todo esse processo formativo, acrescento ainda, os conhecimentos adquiridos com a pesquisa científica através dos projetos que participei. A aprendizagem quanto a escrita de trabalhos científicos, os conhecimentos adquiridos a cada projeto, as viagens para eventos científicos, as pesquisas e levantamentos bibliográficos, tudo isso fará parte do meu currículo, e farei questão de levar também para a minha vida. Lembrar do quanto foi trabalhoso desenvolvê-los torna a minha formação ainda mais prazerosa.

De tudo isso, posso concluir dizendo que sinto como se minha identidade profissional fosse construída gradativamente, num processo que envolve a educação como um todo, onde à minha experiência são adicionadas as leis que regem a educação, a escola como instituição, a identidade do Ensino Médio, o dever da profissão, os desafios da disciplina, eu como agente de mudança da sociedade e os estudantes como um todo e em suas individualidades e o processo de ensino aprendizagem, obtendo como resultado o eu docente.

\section{REFERÊNCIAS}

ANASTASIOU, Léa das Graças Camargos; ALVES, Leonir Pessate. Processos de ensinagem na universidade: pressupostos para as estratégias de trabalho em aula. Univille, 2003.

BERGER FILHO, Ruy Leite. Educação profissional no Brasil: novos rumos. Revista Ibero-Americana, n. 20, 1999.

BRASIL. Lei de Diretrizes e Bases da Educação Nacional. Lei No 9394/96. Brasília: 1996. disponível em: <http://www.planalto.gov.br/ccivil_03/leis/19394.htm> acesso em: 06/04/2015.

BRASIL. Lei no 11.788, de 25 de setembro de 2008. Disponível em: <http:/ / www.planalto.gov.br/ccivil_03/_ato2007-2010/2008/lei/111788.htm> acesso em: 06/04/2015.

BRASIL. Lei 11.892 de 29 de dezembro de 2008. Disponível em: <http:/ /www. planalto.gov.br/ccivil_03/_ato2007-2010/2008/lei/111892.htm> acesso em: 31/01/2017.

BRASIL. Portaria 04 de 06 de janeiro de 2009. Diário Oficial da União. Brasília: MINISTÉRIO DA EDUCAÇÃO (MEC), 2009.

BRASIL. Ensino Médio Integrado à Educação Profissional. Boletim 07. Brasília: MINISTÉRIO DA EDUCAÇÃ̃ (MEC), 2006.

CAMPOS, Edson Nascimento [et al.]; PIMENTA, Selma Garrido (org.). Saberes pedagógicos e atividade docente. 7. Ed. São Paulo: Cortez, 2009. 
FREIRE, Paulo. Pedagogia da Autonomia: Saberes necessários à pratica educativa. São Paulo: Paz e Terra, 1996.

MASETTO, Marcos Tarciso. Competência pedagógica do professor universitário. São Paulo: Summus, 2003.

MAZZIONI, Sady. As estratégias utilizadas no processo de ensino-aprendizagem: concepções de alunos e professores de ciências contábeis. Revista Eletrônica de Administração e Turismo-ReAT, v. 2, n. 1, p. 93-109, 2013.

MOREIRA, Marco Antônio. Aprendizagem Significativa Crítica. Porto Alegre, RS: UFRG, 2010.

PICONEZ, Stela Conceição Bertholo (coord.). A prática de ensino e o estágio supervisionado. 24. Ed. Campinas, SP: Papirus, 2012.

MOURA, Dante Henrique. Educação Básica e Educação Profissional e Tecnológica: Dualidade Histórica e Perspectivas de Integração. v. 2, p. 4-30, mar. 2008. ISSN18071600. Disponível em: <http:/ / www2.ifrn.edu.br/ojs/index.php/HOLOS/article/ view/11>. Acesso em: 10 abr. 2017.

PIMENTA, Selma Garrido; LIMA, Maria Socorro Lucena. Estágio e docência: diferentes concepções. Poíesis Pedagógica, v. 3, n. 3 e 4, p. 5-24, 2010.

PIMENTA, Selma Garrido; LIMA, Maria Socorro Lucena. Por que o estágio para quem não exerce o magistério: o aprender a profissão. Estágio e Docência. São Paulo: Cortez, p. 99-121, 2004. 